\title{
An Underused Treatment Strategy: Voter Enfranchisement
}

\author{
Jonathan Kusner, $B S^{7}{ }^{(1 D}$, Andreas Mitchell, MD, MPP², Bevin Kenney, $M D^{7}$, and \\ Sheridan F. Reiger, MD, MPH
}

${ }^{1}$ Harvard Medical School, Boston, MA, USA; ${ }^{2}$ Department of Internal Medicine, University of California San Francisco, San Francisco, CA, USA;

${ }^{3}$ Division of General Internal Medicine, University of Washington Medical Center - Montlake, Seattle, WA, USA.

J Gen Intern Med 36(3):769-71

DOI: $10.1007 / \mathrm{s} 11606-020-06286-\mathrm{Z}$

(C) Society of General Internal Medicine 2020

$\mathrm{O}$ n November 3, 2020, the USA faces a unique election. This election will occur amidst a historically divided nation confronting a global pandemic and a steepening economic recession, while a national movement for racial justice wages on during an election cycle with a presidential incumbent who was recently impeached. Providers at community health centers (CHCs) are facing unique challenges in this landscape, serving as essential workers themselves while looking for ways to support some of the most vulnerable patients in the nation - many of whom bear the greatest burden of COVID-19, economic recession, and racial injustice, but whose voices are also often left out of the national political conversation. ${ }^{1-4}$ There has never been a more important time for CHCs to amplify the voices of their patients through healthcare-sponsored non-partisan voter registration.

The connection between healthcare and voter enfranchisement has been understudied, leading many healthcare professionals to be uncomfortable with offering voter registration services to their patients. Voter suppression, the act of limiting the ability of eligible citizens to vote, brings the connection between healthcare and voting into stark relief. CHCs often serve populations that are the targets of voter suppression efforts: ${ }^{4}$ the young, those with lower socioeconomic status, and racial and ethnic minorities. ${ }^{2,}{ }^{5-8}$ Well-documented voter suppression targeted at these populations is particularly concerning in light of evidence that these populations demonstrate political preferences that differ from unsuppressed dominant voter groups. ${ }^{9}$ Medicaid expansion is an important example that illustrates this. Across the USA, there are dramatic differences in opinions of Medicaid according to race, with people of color having more favorable opinions of Medicaid

Electronic supplementary material The online version of this article (https://doi.org/10.1007/s11606-020-06286-z) contains supplementary material, which is available to authorized users.

Received March 16, 2020

Accepted October 5, 2020

Published online October 19, 2020 compared to whites. ${ }^{9}$ States with voting barriers that disproportionately affect people of color tended to be those states that rejected Medicaid expansion. ${ }^{2,9,10}$ One startling example is Alabama, in which two-thirds of the population that would benefit from Medicaid expansion (44\% of whom identify as Black) were not registered to vote. ${ }^{9,}{ }^{11}$ Although any healthcare institution may offer voter registration services to patients, CHCs are particularly well positioned to offer these services in light of the demographic overlap between populations that $\mathrm{CHCs}$ serve and those targeted by disenfranchisement efforts.

Social determinants of health $(\mathrm{SDoH})$ are shaped by political systems and economic and social policies. ${ }^{12,}{ }^{13}$ These domains have traditionally been understood to exist outside of health professionals' medical obligations. However, recurrent public and private sector failures that have negatively impacted health like the water crisis in Flint, Michigan, our nation's disorganized response to the COVID-19 pandemic, and the epidemic of police and gun violence in the USA have made it more obvious that SDoH significantly impact the health and wellness of communities. ${ }^{3}$ In recognition of this, many public health and medical professionals have advocated for physicians and hospitals to take an active role in addressing SDoH. ${ }^{14,}{ }^{15}$ Given the demands on physicians' time and attention, many others have been remained hesitant about physicians' role in addressing SDoH. ${ }^{16}$ Non-partisan voter registration has emerged as an important middle path. Directing patients to healthcare-based voter registration is one activity that allows healthcare professionals to elevate the voices of their patients to inform solutions to SDoH in a way that integrates with current healthcare work flows. ${ }^{17-20}$

Healthcare-based non-partisan voter registration does not require physicians and other healthcare professionals to become voter registration experts nor does it involve these individuals sitting down one-on-one with patients to register them to vote. Voter registration will take many forms, depending on clinic and institutional work flows, layouts, and resource commitments, but in all of these cases, healthcare professionals are asked to simply direct patients to highquality resources, sponsored by their institution or clinic, which then take over the process of registering individuals to vote. The concept and implementation of a non-partisan voter registration drive within $\mathrm{CHCs}$ is not novel and has been reported by Liggett et al. in 2012 and by Lickis et al. in 
2018. ${ }^{18,19}$ CHCs are not the only clinical setting where voter registration should take place. National legislation empowers any office providing public assistance, like Medicaid services, to register voters.

In spite of these initiatives taking various forms, there are several best practices that are transferable between voter registration efforts, along with many free online resources that can facilitate this work, some of which we will highlight here. By way of best practice, any healthcare-associated voter registration initiative must be strictly non-partisan with a goal of general civic participation and without any intention of specific partisan gain. To remain non-partisan, specific details of candidates, policy, or issues should not be discussed. Patients can instead be referred to resources, like vote411.org, which compile ballot related information in a non-partisan manner. All efforts should be geared toward participation in the electoral process according to safe voting practices. Sadly, due to past voter suppression efforts, which have occurred along specific demographic lines, contemporary voter enfranchisement efforts are often critiqued as partisan initiatives. The partisan appearance of contemporary voter enfranchisement efforts speaks more strongly to the goals of historic and ongoing voter suppression than it does to the intent of proparticipation, non-partisan initiatives. We believe that healthcare workers should not remain complicit in continued voter disenfranchisement out of concern for partisan optics. Voter suppression in the USA is particularly durable because its solution, voter enfranchisement, is easily misrepresented as a partisan initiative. We believe critics should instead ask why so many citizens within a single party have gone so long without political voice. ${ }^{2,5-7,10,21}$

In addition to non-partisan commitment, voter readiness efforts should unobtrusively engage any and every eligible voter no matter their demographics, broadly defined. This is typically best performed by including site-based materials, like posters and informational fliers in addition to in-person engagement. The design of any healthcare-based voter registration initiative should include the perspective and support of clinic administrators, front office staff, healthcare providers of all professions, and patient advocates in order to ensure sustainability, respect for all, and noninterference with daily patterns of work.

Even with explicit support and energetic buy-in from all of the appropriate groups, voter registration initiatives can be sporadic, lack follow-up, and fail to cultivate an institutional culture of patient empowerment. One strategy to combat this is through the formation of an Institutional Action Plan (IAP) created in partnership between all relevant stakeholders. Such action plans have been popularized by initiatives within higher education, namely Students Learn Students Vote (SLSV). Outlines and examples for IAPs can be found at the SLSV website here: https://www.studentslearnstudentsvote.org/sample-campus-plans. Guided by an IAP, voter registration efforts can be further facilitated by high-quality online resources, many of which are available at no cost. For further support,
National Voter Registration Day partners with organizations of any size and within any sector to provide resources and guidance on establishing voter registration infrastructure. They encourage potential partners to explore their website for more information: https://nationalvoterregistrationday. org/. Two other organizations have demonstrated outstanding leadership in voter registration resource development. Vote. org (https://www.vote.org/) provides free seamless online voter registration, vote by mail application, election reminders, registration confirmation, and many other services tailored to anywhere in the USA. Their platform is free to use and allows for high-level data collection which can assist quality improvement efforts. VotER (https://vot-er.org/) is a nonpartisan voter readiness initiative that specifically seeks to engage healthcare professionals in "inviting (patient) voices into the democratic process." To facilitate this, they offer their Health Democracy Kit, which allows healthcare providers to direct patients to an online voter registration platform that walks patients through voter registration in a state-specific manner. VotER will provide Healthy Democracy Kits to healthcare institutions free of charge.

In order to investigate the feasibility of healthcare-based voter registration, we conducted a month-long voter registration intervention at a $\mathrm{CHC}$ in Boston, MA from October 24, 2017, to November 11, 2017. The CHC that was chosen for this project had a patient population that was $84 \%$ Hispanic or Latino, $14 \%$ reported graduating from college, and $25 \%$ reported food insecurity. This project was implemented in three phases: administrative approval, volunteer recruitment and training, and voter registration. We obtained approval for this project and its study by the CHC leadership and patient advisory board, as well as the Harvard Office of Human Research Administration Institutional Review Board. This registration initiative was staffed by bilingual (English and Spanish-speaking) volunteers who were recruited through local health professions schools. The League of Women Voters, a non-partisan national civic engagement organization, trained volunteers in voter registration. We equipped volunteers with MA-based online voter registration resources (https://www. sec.state.ma.us/ovr/). Encouragingly, although $88.3 \%$ of eligible individuals were already registered to vote, we were able to complete voter registration for 41 other individuals throughout the month. Our experience demonstrated how easily healthcare-based non-partisan voter registration can be coordinated and offered to patients in a way that does not burden providers or interrupt clinic work flows. Ours is only one experience but we hope that it may serve as an example of how non-partisan voter registration may be offered as a healthcare sponsored service to individuals in one's community.

Healthcare professionals around the USA are grappling with their role in our evolving healthcare and social environments. Although political engagement has previously been expunged from the healthcare environment, there are strong links between healthcare and voting. These links make it 
apparent that healthcare providers and institutions have a role to play at the interface of health and voting. Healthcaresponsored non-partisan voter registration is one activity that has been shown to be feasible within a healthcare setting, is well aligned with the goals of healthcare professionals to improve the health and wellness of their communities, and advances patient-centered care through the elevation of patients' voices to inform healthcare solutions. High-quality resources are freely available to healthcare providers and institutions to implement non-partisan voter registration. As the links between healthcare, $\mathrm{SDoH}$, and voting continue to emerge, we believe that those in healthcare will increasingly recognize their responsibility to elevate the voices of their patients: voting is the standard of care.

Corresponding Author: Jonathan Kusner, BS; Harvard Medical School, Boston, MA, USA (e-mail: Jonathan_kusner@hms.harvard. edu).

\section{Compliance with Ethical Standards:}

Conflict of Interest: The authors declare that they do not have a conflict of interest.

\section{REFERENCES}

1. Richard B, Jr AO, Gebeloff R, Lai KKR, Wright W, Smith M. The Fullest Look Yet at the Racial Inequity of Coronavirus. 2020.

2. Clark J. Widening the Lens on Voter Suppression From Calculating Lost Votes to Fighting For Effective Voting Rights. Haas Inst a Fair Incl Soc. 2018;(July).

3. Braveman $\mathbf{P}$, Gottlieb $\mathbf{L}$. The social determinants of health: It's time to consider the causes of the causes. Public Health Rep. 2014;129(SUPPL. 2):19-31. https://doi.org/10.1177/00333549141291s206

4. Nath JB, Costigan S, Hsia RY. Changes in demographics of patients seen at federally qualified health centers, 2005-2014. JAMA Intern Med. 2016;176(5):712-714. https://doi.org/10.1001/jamainternmed.2016. 0705

5. New Voting Restrictions in America. www.brennancenter.org. https:// www.brennancenter.org/sites/default/files/2019-11/New Voting Restrictions.pdf. Published November 18, 2019. Accessed December 30 2019. http://www.brennancenter.org/new-voting-restrictions-america.
6. Matt A. Barreto and Gabriel R. Sanchez, Accepted Photo Identification and Different Subgroups in the Eligible Voter Population, State of Texas, 2014, Expert report submitted on behalf of plaintiffs in Veasey v. Perry, June 2014.

7. Liptak A. Supreme Court Won't Restore 'Golden Week' Voting in Ohio. New York Times. https://www.nytimes.com/2016/09/14/us/politics/ supreme-court-wont-restore-golden-week-voting-in-ohio.html. Published September 13, 2016.

8. North Carolina, et al., Petitioners v.North Carolina State Conference of the NAACP, et al. No. 16-833 U.S. 1, 30 (2016). https://doi.org/10.1093/ iclqaj/11.4.976

9. McElwee S. Health Care Policy Is Undermined by Voting Barriers. Century Found. 2018:1-16. https://tcf.org/content/report/health-care-policyundermined-voting-barriers/. Accessed Feb 2020.

10. Ii BLR, Spencer DM. Passive voter suppression. 2019

11. The Kaiser Family Foundation State Health Facts. Data Source: The Centers for Disease Control and Prevention (CDC), National Vital Statistics Reports (NVSR), Vol. 66, No. 1 FY2013. J Conserv Dent. 20(2).

12. Marmot M, Friel S, Bell R, Houweling TA, Taylor S. Closing the gap in a generation: health equity through action on the social determinants of health. Lancet. 2008;372(9650):1661-1669. https://doi.org/10.1016/ s0140-6736(08)61690-6

13. Social Capital as a Health Determinant: How is it Measured? Policy Res Div Strateg Policy Dir Popul Public Heal Branch, Heal Canada Heal Policy Work Pap Ser. 2003;(March): 1-34.

14. Sullivan HR. Hospitals' Obligations to Address Social Determinants of Health. AMA J Ethics. 2019;21(3):248-258. https://doi.org/10.1001/ amajethics.2019.248

15. Marmot M. The health gap: Doctors and the social determinants of health. Scand J Public Health. 2017;45(7):686-693. https://doi.org/10. $1177 / 1403494817717448$

16. Maani N, Galea $\mathbf{S}$. The Role of Physicians in Addressing Social Determinants ofHealth. J Am Med Assoc. 2020;323(16):1551-1552. https://doi.org/10.1056/NEJMms 1814262

17. Milligan M, Jones D. Voting and the Role of Physicians. Acad Med. 2017;92(9): 1220 .

18. Liggett A, Sharma M, Nakamura Y, Villar R, Selwyn P. Results of a voter registration project at 2 family medicine residency clinics in the Bronx, New York. Ann Fam Med. 2014;12(5):466-469. https://doi.org/ 10.1370/afm. 1686

19. Lickiss S, Lowery L, Triemstra JD. Voter Registration and Engagement in an Adolescent and Young Adult Primary Care Clinic. J Adolesc Heal. 2020;66(6):747-749. https://doi.org/10.1016/j.jadohealth.2019.11.316

20. Grande D, Asch DA, Armstrong $\mathbf{K}$. Do doctors vote? J Gen Intern Med. 2007;22(5):585-589. https://doi.org/10.1007/s11606-007-0105-8

21. Hajnal $\mathbf{Z}$, Lajevardi $\mathbf{N}$, Nielson $\mathbf{L}$. Voter identification laws and the suppression of minority votes. J Polit. 2017;79(2):363-379. https://doi. org/10.1086/688343

Publisher's Note Springer Nature remains neutral with regard to jurisdictional claims in published maps and institutional affiliations. 